\title{
UN “CLASH” VELAZQUINO EN EL ÚLTIMO BAUDELAIRE, O EL TIQQUN DEL NUEVO INGENUO*
}

\author{
David Fiel \\ Universidad Nacional de la Patagonia San Juan Bosco \\ Universidad Nacional de La Plata \\ ponycalamity@gmail.com
}

Resumen: El presente artículo versa principalmente sobre el contenido político del poema en prosa "Azotemos a los pobres". También se establecen a partir de este pivote central algunas relaciones entre el último y los anteriores períodos de la poesía baudelairiana, destacando el hecho de que la idea de una República real iba haciéndosele al poeta cada vez más imposible conforme los años transcurrían y Francia se hundía en las blanduras (que eran asimismo crudezas) del Segundo Imperio. Dándole a este escrito, sobre todo hacia el final, un sesgo más especulativo e interpretativo, aunque sin abandonar la perspectiva baudelairiana (que no es otra que la que sus mismos textos permiten inferir), se considera también que quizás el desenlace del Segundo Imperio haya sido para el poeta la más estruendosa manifestación de aquella imposibilidad política.

Palabras clave: Baudelaire, Historia, Poesía, República.

\begin{abstract}
In this article I consider the political meaning of one of the last Baudelaire's prose poems, "Let's beat up the poor!" Establishing some relationships between the last and previous periods in Baudelaire's poetry, with the idea of the impossibility of a real Republic in mind (as, besides, Baudelaire himself was always very careful to let the reader know, in particular through his writings from 1851 on), I get into a more interpretive path, suggesting that perhaps the Second Empire was itself, for him, the flashiest expression of such impossibility, as the poet was mournfully chewing on during his last years.
\end{abstract}

Keywords. Baudelaire, History, Poetry, Republic. 


\section{I}

Las secuencias del poema en prosa "Azotemos a los pobres" (1865) son quijotescas en su disposición: el solitario sale de una reclusión de quince días en su comunidad imaginaria, para visitar la sociedad y entregarse al Espectro, al Número (Número y Espectro que tanto le habían dado que pensar, que lamentar a Baudelaire). El descenso de la buhardilla, ensayado en tiempos del poema "Paisaje", primero de la sección segunda de Las flores del mal (OC I, 82), ya no deja al poeta ante el abierto de la ciudad (OC I, p. 83; "Sol"), lecho natural de aquel Número y de aquel Espectro; por el contrario, este neoQuijote es hijo del hastío y pasa sin transición de la retención melancólica a una hiperactividad sin sentimentalismos: en la breve pero intensa aventura de una tarde belga, el poeta conocerá su misión, "desfacer los entuertos" de la condición humana, política, en el cuerpo de un mendigo (que es también un ciudadano, es decir un mito) hallado por azar a la entrada de un cabaret. ¿Se habrá tratado de una mera ficción? En una carta a Félix Nadar, fechada en Bruselas el 30 de agosto de 1864, el poeta declaraba: "¿Me creerías si te dijese que yo he podido golpear a un belga? Es increíble, ¿no? Suponer que yo pueda golpear a alguien, es absurdo" (itálicas de Baudelaire; CG II, p. 401). Una nota explicativa de Pichois decide dirimir el problema genético: "Esta anécdota (¿vivida?) es sin duda el germen del pequeño poema en prosa” (p. 873). ¿Pero cómo supo esto Pichois? No hay pruebas ni en una dirección ni en la otra; todo podría ser cierto, tratándose de Baudelaire: como verdad, el hecho habría sido otro capítulo más en la saga de sus $N^{\circ}$ 8. Primer Semestre de 2018 
actos de transformación del barro de la ciudad en un oro poético (de acuerdo con la metáfora del "Epílogo" a Las flores del mal); como mentira, el hecho habría podido ser otra inflexión mistificadora más, actitud tan frecuente en el poeta, como se sabe. La controversia, en todo caso, no suprime sino que refuerza ese estado de ambigüedad en el que las cosas se mantienen siempre en Baudelaire.

En el texto, el poeta se presenta en la situación inicial de unas ciertas lecturas políticas que lo habían decepcionado; este momento pre-caballeresco (pre-quijotesco) del sujeto, constituye algo así como la historia preparatoria de sus posteriores acciones de reivindicación. Ficciones políticas que muy engañosamente se le habían ofrecido a él como realidades inobjetables, correspondía por tanto enmendarlas, luchar contra los monstruos que esos sueños desmesurados habían producido en plena calle; correspondía iniciar una crítica que procediese por vía de acción (vieja intuición baudelairiana, por otra parte, formulada desde hacía años en su Salón de 1846: "la mejor reseña de un cuadro podrá ser un soneto o una elegía"; OC II, p. 418). El poeta siente entonces la necesidad incoercible de salir a liquidar los efectos de esas ficciones, de modo que, de improviso, él se "arma caballero" en un diálogo apresurado con su propio "demonio", que él intuye de naturaleza anti-socrática, no apolíneo sino dionisíaco, "un demonio de acción" (OC I, p. 358). Ni bien cesa este diálogo no transcrito, el poeta se coloca ante el blanco de su intervención: un mendigo estacionado junto a la puerta de esa moderna venta, el cabaret belga. Acto seguido, motivado por la doctrina sucinta, precisa, que su "demonio de acción" le había 
comunicado hacía instantes, el poeta pasa a propinarle al mendigo unos cuantos golpes de puño, destinados a galvanizar la consciencia ciudadana del miserable (a "despertarla", habría dicho Victor Hugo), quitándola de su modorra republicana. En este preciso momento, la "antigua carcaza" (p. 359), parada repentinamente sobre sus pies a fuerza de puñetazos, atina a contestarle en los mismos términos al poeta, cuando el instructor lo detiene con un gesto y unas pocas palabras; su sola reacción significa para él que la lección de dignidad ha sido aprendida, pues, de acuerdo con la voz inspiradora del demonio, "sólo es el igual de otro quien puede probarlo, sólo es digno de su libertad quien sabe conquistarla" (p. 358).

Sabemos por la historia del manuscrito, que la frase final del texto original había sido suprimida por los primeros editores póstumos del texto, Asselineau y Banville. La frase decía, significativamente: "¿Qué piensas de todo esto, ciudadano Proudhon?" La memoria del republicano, demócrata, socialista y a su modo providencialista ateo (practicante de otra "religión sustitutiva", la del Progreso), estaba demasiado fresca todavía en las memorias del día como para tolerar que se arriesgase públicamente su nombre de ese modo irreverente empleado por Baudelaire en su texto; y nada se custodia más en las repúblicas que el recuerdo sacrosanto de su más querida gente, sobre todo porque a estas estructuras impersonales les resulta casi siempre difícil, o inconveniente, honrarlos con la recuperación de sus acciones y propósitos. 
El poema en prosa habría podido ser leído como una misiva dirigida a este filósofo que acababa de morir cuando Baudelaire (quien años atrás, por otra parte, había llegado a tratarlo; un par de cartas fechadas en París el 21 de agosto de 1848, dan testimonio de ese contacto; CG I, pp. 150-2) había iniciado la redacción de su escrito. El poema habría narrado para Proudhon (excepto que la amputación por los editores de la frase final, impide para siempre esta posición, y el poema en prosa deberá flotar entonces como una "carta sin dirección", postal imaginaria o cuento) la repercusión veinte años posterior, en una calle de Bruselas una tarde, de los acontecimientos del París revolucionario de 1848, escena protagonizada por un agente furtivo (la ficción de este Baudelaire-personaje, precisamente) que sólo se decide a irrumpir en la arena pública para realizar, sobre el cuerpo de un disminuido partenaire y al amparo de la ocasión, su propia guerrilla de uno, su anarquismo de cámara.

La amputación de la mencionada frase, sin embargo, de ningún modo desentona con la historia general del texto. El rechazo, en él, es parte constitutiva de la lógica que lo sustenta como pequeña totalidad, e incluso del contexto en el que se creó; rechazos que son, por otra parte, internos y externos, implícitos y explícitos. El texto rechaza explícitamente nombres de científicos y de políticos del día, en una suerte de gesta, no menos quijotesca, contra la avasallante exigencia de objetividad, propia de aquel siglo (F. Schlegel, Novalis, ya 
habían dejado testimonio desde hacía años de esta molesta exigencia colectiva legada por el primer post-kantismo; p. 66). Internamente, el texto rechaza los nombres de Lélut (autor de una monografía llamativamente titulada El Demonio de Sócrates, publicada en 1836 y que Baudelaire probablemente consultó) y de Baillarger (autor de importantes tratados médicos que hallarían respuesta en Los paraísos artificiales; entre ellos, el Ensayo de clasificación de las enfermedades mentales, publicado en 1854); el texto rechaza también los nombres (implícitos) de varios autores políticos del día, inspirados en el "catecismo republicano" de la hora revolucionaria; estos políticos habían propuesto algunos de los disparates que el poeta resumía sarcásticamente al comienzo de su poema, apuntando visiblemente tanto contra liberales como contra demócratas, versiones igualmente bochornosas, para este Baudelaire swiftiano en su manera de encarar el presente, del ruidoso, verborrágico acreedor de la gran deuda republicana de más de medio siglo de historia: 'Yo había digerido o más bien tragado, debería decir, todas las elucubraciones de esos empresarios de la dicha pública, que aconsejan a los pobres volverse esclavos o que los persuaden de ser reyes destronados" (OC I, pp. 357-8). La edición póstuma del poema había rechazado a su vez, amputándola por completo, la frase más arriba citada en la que el nombre de Proudhon aparecía. Pero esto no es todo: el poema entero había sido objeto de rechazo por parte de la "Revista nacional" a la que el poeta lo había destinado en su primer intento de publicación. Dirigida hasta 1865 por Philippe Buchez (quien también moriría ese mismo año, como Proudhon), la revista en cuestión sería el capítulo final en la 
historia personal de este viejo saint-simoniano y anterior carbonero que, arrastrado por sus fuertes convicciones sociales, se tornaría republicano liberal y más tarde de izquierda durante la Monarquía de julio, e incluso, luego aún, republicano providencialista (fuertemente católico) por 1848, no exactamente al estilo del ateo Proudhon, por cierto, aunque sí, al igual que éste, depositando en la idea de Progreso toda esperanza de salvación humana en la Tierra.

Es posible especular sobre este último rechazo, implícito y exterior, de que el poema fue objeto por parte de la "Revista nacional" de Buchez. El poema proponía entre otras cosas la inversión paradójica de la limosna ("paradoja de la limosna", había escrito el poeta en El arte filosófico; OC II, p. 607), que no consistiría ya en unas pocas monedas destinadas a asistir por un rato la miseria de un pobre, sino en la instrucción violenta, para-estatal (un cierto flirteo anarquista, muy sutilmente proproudhoniano, parace manifestarse aquî), llevada a cabo por un agente inopinado y secreto (Baudelaire-personaje) y resuelta en unos golpes directos propinados sobre el cuerpo de un políticamente desahuciado, muy adormecido (aunque de inmediato despierto) mendigo. Liberado violentamente de su alienación, el miserable podría por fin levantar el guante de aquella arenga con la que Victor Hugo, más de diez años atrás y en su propio exilio belga, había desafiado la comedia del inminente Segundo Imperio: "Es tiempo de que la consciencia humana despierte", había escrito Hugo en Napoléon le Petit (I.3). En un estilo que recuperaba la contestación protestante de Étienne de la Böetie, gran antecedente de las rupturas profanas de consciencia en Francia, Hugo suponía tal vez, en este libro 
suyo de 1851 (casi como si la fuerza de las ideologías no existiese aún para él, o como si el sujeto viviese todavía en un estado pre-ideológico de consciencia política), que el adormecimiento de la costumbre de obedecer podía suprimirse con el simple gesto de "despertar", condición inicial y suficiente para todo paso inmediato al acto liberador, que de pronto parecía darse de suyo sin otra mediación práctica que el despertar mismo. La posición de Marx, expresada en La ideología alemana (producto también de otro exilio belga, contemporáneo al de Hugo, por otra parte), posición según la cual "no es la consciencia la que determina la vida sino la vida la que determina la consciencia", no parecía estarle permitida al idealista a ultranza de Las contemplaciones. En todo caso, la frase final del manuscrito baudelairiano, borrada por sus editores, habría hecho del poema, en caso de haber subsistido como tal, un objeto curioso que quizás no le hubiese disgustado del todo al Marx del tratado anti-proudhoniano (y también belga), La miseria de la filosofía.

La "Revista nacional", cuya redacción había rechazado la publicación del texto de acuerdo con el primer manuscrito, le pertenecía al mencionado Buchez, es decir nada menos que al primer presidente de la Asamblea Nacional Constituyente de 1848, al primer elegido por el sistema de sufragio universal masculino promulgado ese mismo año. Este personaje público había contribuido además a promover los "Talleres nacionales", gran organización de contención para desempleados cuyo cierre intempestivo había motivado las anti-populares (y crueles) "Jornadas de junio" de 1848, y que antes, durante toda la década de 1840, había sido el fundador 
del periódico obrero "L’Atelier", "órgano especial de la clase trabajadora, redactado exclusivamente por trabajadores", según rezaba su epígrafe. Era improbable que el editor de un foro gráfico de esta naturaleza, en cuyas páginas se había amasado buena parte de la ideología republicana de tendencia demócrata-socialista, celando sus distancias tanto respecto del comunismo anticatólico y antidemocrático de Blanqui (Buchez era católico confeso y asambleísta hijo de las elecciones democráticas, que Blanqui repudiaba) como del republicanismo liberal lamartiniano, que vinculaba con insolencia demasiado pequeño-burguesa la libertad individual a la posesión del oro (W. Benjamin citaría esta insolencia en la primera parte de su ensayo "El París del Segundo Imperio en Baudelaire"; en Charles Baudelaire. Un poète lyrique à l'apogée du Capitalisme, p. 50), publicase un texto notoriamente enemigo de toda forma de republicanismo y manifiestamente devoto, en cambio, de la perversión política de unas revueltas en parte individualistas y en parte cuasi-anárquicas y para-estatales, como la que Baudelaire insinuaba en su texto. (Un amigo de juventud del poeta, Charles Toubin, ya había registrado este tipo de animadversiones, siempre adyacentes en Baudelaire a argumentos que las contradijesen: "aunque no republicano, él solía lucir una corbata roja"; La jeunesse de Baudelaire vue par ses amis, p.132. Excelente testimonio que habla toneladas acerca de las ambigüedades que el poeta promovía, en este caso lanzando la moda que él mismo solía vestir, en contra de posiciones que él mismo decía sostener, y todo ello compactado en un mismo portador al que por tanto cabía preguntarle, en sus propios términos, “¿Cuál es la verdadera?”; OC I, p. 342). 
No un lugar de mero conformismo pequeñoburgués, entonces, sino un modo casi proudhoniano de articular la izquierda, era lo que "L'Atelier" hacía por aquellos años prerevolucionarios, acentuando el carácter social del movimiento obrero al promover el derecho al trabajo y al mismo tiempo proponiendo la necesidad de un orden que le debiera sus consignas morales a la tradición bien-pensante de los herederos de 1792. Buchez era un ejemplo conspicuo de esta clase de "honnête homme", y Baudelaire, en su tardío poema en prosa de 1865, planteaba algo inadmisible para toda posición moral que, a la manera de Buchez (pero también de Proudhon), depositase sus esperanzas políticas en la idea de Progreso. Al componer la alegoría de un desahuciado que, instruido por la intervención imprevista de un agente secreto, realizaría por sí y para sí aquello que la historia le había negado (a él, pero también al otro cuerpo, no menos golpeado, de la República), Baudelaire se convertía en un inadmisible para los espíritus positivos del día, fuesen ellos de derecha, de centro o de izquierda. La "teoría" eudemonista de este agente secreto, según la cual "sólo es el igual de otro quien puede probarlo y sólo es digno de su libertad quien sabe conquistarla", traía muy obscenamente a cuento la memoria de la acción colectiva perdida o traspapelada en el curso de aquellos acontecimientos que remontaban su primera nostalgia hasta 1789 pero sobre todo a la Primera República, trunca, de 1792 (y trunca por segunda vez a partir de 1851). De acuerdo con la alegoría del poema, esta acción perdida o extraviada podía serle expropiada a la historia, de improviso y una tarde cualquiera, y además por cualquier miserable que anduviese por allí y que hubiese sido 
alertado por la intervención inopinada de cualquier agente secreto, perverso promotor de sublevaciones "ready-made". Así como el abismo interior de Manfred había pasado, con Baudelaire, al mundo de los traperos, de los viejos, prostitutas, jugadores, ciegos y demás "vencidos" del mundo, también la historia, sus bienes políticos, sus promesas y deseos, podían ser repartidos por la tarde como panfletos de un centavo en las esquinas de cualquier calle. Entregadas impúdicamente a un presente que, por definición, era en sí mismo intratable, las reivindicaciones más legítimas de la historia resultaban ser, de este modo, in-encuadrables en el interior de no importa qué ideologías, e imposibles de someter a no importa qué proyectos partidistas. La acción del poema en prosa ponía de relieve descarnadamente el residuo social de un pobre que, como de la nada ("al entrar a un cabaret", se lee en el texto), aparecía expuesto en una suerte de Getsemaní histórico que consagraba la imagen alegórica de la intemperie absoluta de la pobreza, y al mismo tiempo proponía una versión de los hechos inaceptable para cualquier postura progresista (la cual de muy buen grado habría aceptado considerar a los elementos sociales más desgraciados de la nación, siempre y cuando se le permitiese incluirlos de inmediato en alguno de los tantos proyectos de salvación que desde la década de 1840 habían surgido con el expreso fin de adueñarse de esos modos extremos de existencia). Invitando al sujeto marginal a realizar solitariamente todo lo que la política no había sabido hacer por él, y también estimulando en éste una actitud que lo hiciera merecedor de todo aquello que la charlatanería republicana, de izquierda o de derecha, le había prometido pero no había 
sabido darle, el poema desnudaba el gran tabú de la vida social $y$ en general de las ficciones electivas, ese bien de todos los bienes políticos de acuerdo con el comunista utópico Étienne Cabet: la igualdad real; no la natural, que tan sólo en hipótesis había entrado en el derecho positivo de Francia desde la Convención de 1791; menos aún la formal o jurídica, probadamente ficticia en la práctica.

La relación ocasional, ese choque de ribetes surrealistas (lautremontianos) entre un paraguas y una máquina de coser, entre un desfasado y muy anacrónico agente secreto, polizón perverso de la historia al que un demonio de acción había inspirado, y un pobre cualquiera, realzado en la escena por contornos casi caravaggistas (un sobreviviente, sin duda, de aquellos tiempos de 1848 en los que el miserable habría sido otro más de los tantos obreros peticionarios de los "Talleres nacionales" de Buchez), ponía de manifiesto el fracaso de la política de cara a lo real, cosa que un activista de raza como Buchez debió haber hallado muy difícil de aceptar, sobre todo cuando toda su vida había sido consagrada, precisamente, a una obstinada militancia en favor de los desposeídos. Pero un antiguo "embriagado" de 1848 (tal como Baudelaire se había definido a sí mismo en sus Diarios intimos; OC I, p. 679), un norepublicano sediento de igualdad real, no tendría empacho alguno en enrostrarle a la historia imperfecta de su nación, a esa amante infiel de la que ahora correspondía vengarse, las perversas "salidas del texto" oficial, mistificador, que su poema proponía y que aquel tipo de encuentros inopinados relataban desde la posición de un ingenuo o literal paranoico, del 
correspondiente decepcionado de Proudhon, de un etnógrafo inventor de "escenas antropológicas".

Bien podría sostenerse, por lo demás, que los dos demonios del poema constituyen algo así como la superación chistosa tanto de la parte proudhoniano-rousseauniana como de la parte demaistriana que competían explícitamente por adueñarse de la voluntad del agente secreto en la psicomaquia política que Baudelaire-personaje, a la manera de un Quijote momentáneo, intermitente, fingía protagonizar. La bondad, la esperanza, la fe en la doctrina, o bien el realismo impiadoso, el sarcasmo, la risa cruel que desgarraba la túnica santa de una justicia puramente abstracta (de su "promesa de felicidad"); creer o no creer en la política, en la idea de República, en la doctrina del Progreso; aceptar o no aceptar las demoras infinitas que la ideología le ponía siempre a la acción, a la manera de una panacea transitoria que compensase por un rato (cosa ilusoria) la imposibilidad de una cura franca y total de la enfermedad histórica de la nación y del sujeto; esa parecía ser la cuestión del texto, al menos en parte.

\section{III}

En rigor, la alegoría del poema de 1865 resultaba ser, además, una suerte de demorada auto-ironía. En su Salón de 1846 Baudelaire se había mostrado tomando no poco regocijo al pedirle a un "municipal de su corazón" que no cesara de "apalear al republicano enemigo de rosas y perfumes" (OC II, p. 490). ¿De qué clase de republicano se trataba entonces, por 
1846? Si una sublevación tomaba de rehén, por puro azar, al "flâneur" ocioso que circulaba por las calles pero que también conservaba vivo el valor de las "florerías y perfumerías públicas" (ibíd.), entonces la única justicia pasaba por implorar el castigo de estos piqueteros que interrumpían el deleite del solitario (la "ensoñación del paseante") y que además "no querían trabajar como obreros anónimos y humildes, sino que pretendían ser libres" (ibíd.); era el republicano de izquierda, "personaje de comedia" (ibíd.), y no ya el republicano rancio, liberal (amigo natural, como Lamartine, de aquellas rosas y perfumes), era el pequeño-burgués que solamente tenía sentidos para su oro y amor por su propia libertad, quien ocupaba la mira estética del joven poeta de 25 años. ¿Estaba entonces este Baudelaire, por 1846, del lado de la Monarquía de julio y de la represión municipal, a la que sarcásticamente aludía llamándola "guardiana de la somnolencia pública" (ibíd.)? De ningún modo así; la distancia política entre Baudelaire y los socialistas y republicanos de izquierda, o entre Baudelaire y el régimen del rey-ciudadano Luis-Felipe, se medía por entonces no en términos políticos sino en términos estéticos, es decir, en los términos de una distancia reactiva, de base humoral; ella ponía en juego la parte "dandy" de su persona, en proceso de despreciar a la parte "útil" de la vida civil ("fanáticos de los utensilios", escribe el poeta en la misma página del mencionado Salón para referirse a aquellos sublevados). "Azotemos a los pobres", poema 49, anteúltimo en la colección póstuma y veinte años posterior al Salón de 1846, data de una fase en la que la distancia no era ya una expresión reactiva o humoral sino en todo caso irónica, la 
manifestación de un desencanto que introducía mediaciones infinitamente recursivas entre el sujeto y el presente. La conversión de una distancia reactiva en una distancia irónica no fue un hecho menor en el curso de su vida; podría decirse, incluso, que su entera obra ha reflejado esto de diversos modos. Esta conversión había llegado a moldear su completa relación con la estética: mientras la reacción humoral gobernó su espíritu, cuando la Belleza bizarra, exótica, parecía ser el centro excluyente de sus inquietudes, el republicano constituía todavía un objeto algo difuso o emblemático en la medida en que el poeta condensaba en esa "figura de comedia" (no indigna de Molière) su desprecio hacia la moral "juste-milieu" (OC I, p. 549) de tiempos de la Monarquía de julio; sin embargo, una vez que, tras el desencanto que sucedió inmediatamente al golpe de 1851, la actitud reactiva devino irónica en él (una ironía que iría parcialmente tiñéndose de piedad con los años), haciendo que la Belleza bizarra y exótica de antes se transformase en una Belleza mezclada al Sublime piadoso de la ciudad (más o menos a partir de 1853), el republicano pasaría a ser la suma existencial del destino general de decrepitud, experimentado por un mundo que se le aparecía al poeta como una totalidad irrecuperable, irredimible ("Cosa bien absurda el Progreso, puesto que el hombre, como los hechos diarios lo prueban, es siempre el semejante y el igual del hombre", había anotado Baudelaire en el folio XIV de Cobetes; OC I, p. 663).

Los golpes dados por los Estados sobre los sujetos, el golpe ocasional con el que algún sujeto arriesgado inquietaba a veces al Estado, e incluso el golpe de un sujeto sobre otro 
("Necesidad de golpear a las mujeres", escribió Baudelaire en el folio XXXVIII de Mi corazón al desnudo; OC I, p. 701), todos ellos tuvieron alguna historia en Baudelaire. El Baudelaire reactivo de 1846, el conspirativo de 1848 y el preceptor anarquista de 1865, ${ }^{1}$ procedieron por vía del golpe ("En política, un verdadero santo es aquel que azota al pueblo por el bien del pueblo", anotaría el poeta en el folio VIII de Cohetes; OC I, p. 655). ¿Qué le pasaba a Baudelaire con los azotes, los apaleos y los golpes? Al igual que con sus voces múltiples, tan plurales como movedizas ("polifónicas sin ser orquestales", según la observación aguda de du Bos), importa considerar también la "voz" del golpe, quién se proponía cada vez como el golpeador de quién, y en qué momento; corresponde considerar la función misma del golpe, su retórica. En 1846, el republicano de izquierda, contestatario, debía ser golpeado por el oficialismo de Luis-Felipe, cosa solamente comprensible si el poeta parecía estimar que dicha voz emergente y rebelde portaba ya los gérmenes de la futura mentira y de las supercherías que los sucesos posteriores no cesarían de convalidar para cualquier observador que lograse prescindir del filtro de una esperanza excesiva o que se arriesgara a ejercer "el ridículo de un profeta" (OC I; p. 667). En 1848 había que tomar el poder a fin de liquidar toda forma de autoridad,

\footnotetext{
${ }^{1}$ En su comentario pormenorizado a Le Spleen de Paris, Patrick Labarthe llamó a este Baudelaire un "terapeuta cínico" (p. 99). Este apelativo constituye a mi entender un error de apreciación. Ni la terapia ni el cinismo son pertinentes aquí, puesto que jamás se trató para el poeta de reconciliar o de integrar a la sociedad a aquel pobre en cuestión (en todo caso lo contrario), ni se trató tampoco de hacerle una burla de cualquier tipo: se sabe bien qué tipo de reacciones suscitaba en Baudelaire el cinismo (valgan los casos de "El bromista" o de "La falsa moneda" como prueba). Ninguna de las cualidades que esos epítetos transmiten, formaban parte de la personalidad de alguien que se dedicaba a elaborar en plena calle sus "bufonerías piadosas".
}

$N^{\circ} 8$. Primer Semestre de 2018 
padrastro incluido; es sintomático que para esta criatura inagotablemente contradictoria que lograba combinar "al impío y al jesuita" en una misma persona ( $L$ a jeunesse de Baudelaire vue par ses amis, p. 134), el conato conspirativo tomase nombre propio justo cuando el objeto de asalto había llegado a ser por una vez genuino en términos públicos, generales. En 1865 había que golpear a los miserbales; en efecto, la doctrina republicana de 1848 había extendido a la totalidad de la ciudadanía, en hipótesis libre, un cheque al portador en el que figuraba la cifra enorme de la igualdad y de la fraternidad, cheque que esa ciudadanía, no obstante, sería siempre incapaz de cobrar en ningún banco, histórico o político. La audacia de este obsequio aumentaba todavía más si su portador era un pobre, alma última de Estado o límite extremo de los efectos bio-políticos de un poder que había vuelto a ser estructuralmente (no nominalmente) monárquico. Este retroceso político encontró su reflejo exacto en el espejo estético que Baudelaire no cesaba de levantar ante las formas cambiantes y siempre monstruosas del presente. Si el quijotismo había sido sustituido por el bovarismo de tiempos de la Monarquía de julio, entonces el retorno estructural a la monarquía en tiempos del Segundo Imperio, debía reponer otra vez, en buena lógica, el quijotismo en la escena. La reformulación en Baudelaire del viejo quijotismo continuo como un neo-quijotismo intermitente, fragmentario, como plan de asaltos furtivos o de guerrillas retráctiles al estilo de la practicada por el poeta a la entrada del cabaret belga, estaba en consonancia perfecta con la forma bio-política imperial, 


\title{
estructuralmente neo-monárquica, que Francia había reasumido bajo Luis Bonaparte. ${ }^{2}$
}

\author{
Si el golpe de la historia sobre el presente había puesto, uno \\ junto a otro, el paraguas a medio abrir del republicanismo \\ trunco de 1848 y la máquina de coser del Segundo Imperio, \\ este "clash" político debía ser contestado con el "clash"
}

$2 \mathrm{El}$ neo-quijotismo de tiempos republicanos fue por fuerza guerrillero, intermitente, puesto que por entonces la consciencia continua del antiguo ingenuo (del viejo "gullible" swifto-voltairiano) no habría podido subsistir ya bajo los nuevos Estados, que demandaban bio-políticamente al sujeto de un modo notoriamente continuo. Esta demanda, de hecho (esta corriente continua de solicitaciones ideológicas), forzó a aquel ingenuo anterior a devenir un ironista, es decir un atacante furtivo de los Estados. Este hecho explica la razón por la que la literalidad quijotesca había sido muy intermitentemente irónica y sólo humorística de modo continuo; los contextos monárquicos o de soberanía autocrática aplicaban sobre el sujeto una presión biopolítica todavía demasiado discontinua como para que el sujeto, a fin de repeler esa presión espaciada, echase mano a medios de defensa más fuertes que el mero humor. Como nuevo tipo de respuesta a la opresión del poder, la estrategia de defensa retráctil de las ironías irrumpió en la economía que rigió las relaciones entre el sujeto y el Estado a lo largo del s. XIX, una vez que la separación entre ambas posiciones se tornó irrescatablemente ambigua, es decir cuando el sujeto dejó de ser un súbdito absoluto para pasar a convertirse en un híbrido político: en parte un continuador de la condición previa de súbdito, y en parte, precisamente merced a la intervención de las ideologías, un emancipado aparente (figura que el "rey destronado", mencionado por Baudelaire en su poema, condensaba con eficacia). En este sentido, era la estrategia de la literalización, pero no el método de ataque (que pasó de ser continuo a intermitente), aquello que se conservaba idéntico entre el quijotismo de tiempos monárquicos y el neo-quijotismo de tiempos republicanos; porque sólo con la "multiplicación de los entes" que el ingenuo o literal llevaba a cabo con espontaneidad, la letra de las promesas políticas podía ser acusatoriamente plegada sobre sus irrealizaciones manifiestas. Ahora bien, mientras que en Cervantes, todavía, la deuda a contraponer al presente defectivo seguía siendo de un orden puramente moral, Baudelaire estaba ya en condiciones de citar la pre-historia de un orden narrativo por completo diferente en su naturaleza como argumento de contraste: su Amadís de Gaula, por así decir, había pasado a ser la historia que la Declaración de los derechos del hombre de 1789 había inaugurado, y en particular todo ese "romanesque" que había tocado uno de sus más heroicos picos en la Convención constitucional de 1792, responsable de haber sancionado la Primera República. Le bastaba a este nuevo ingenuo o nuevo literal, a fin de conseguir el efecto buscado (desnudar la hipocresía del siglo), con oponer, de ese modo entre fugaz e intimidatorio, perverso, que Baudelaire ilustraba, la condición de los miserables dejados en tendal por la historia reciente, al fuerte bullicio ideológico post-revolucionario, bonapartista, restaurador y por supuesto (sobre todo) republicano.

Nº 8. Primer Semestre de 2018 
estético del asalto furtivo en el cabaret, que el poema en prosa proponía. El golpe baudelairiano de 1865 (se comprende entonces) había sido un golpe directo a la pesadilla de las ideologías, malos sueños colectivos que jamás se confundían en el poeta con los sueños puros, inspiradores de aquella acción perdida que en hipótesis había salido a la busca de la República perfecta, y que quizás la encontraría algún día en un recodo secreto de la historia (o no). Dicho golpe había sido pensado por Baudelaire para serle propinado no ya a un Estado indiferente, sino a los cobradores potenciales del cheque ideológico, a aquellos cuerpos en los que con mayor contundencia se reflejara la coyuntura de la ficción republicana, al hallarse ellos corporalmente atrapados entre la mentira palmaria de los discursos igualitarios y fraternitarios, y su propia miseria material. La única manera de tomar por asalto a esta política, consistía para el poeta en propinarle golpes hipermorales a esas ideologías, en asaltar el cuartel central, discursivo, de las supercherías republicano-democráticas, no en un enfrentamiento partidista sostenido en el nivel discursivo mismo de dichos "sistemas de creencias", sino como acción abrupta, como contragolpe individual aplicado sobre sus más evidentes víctimas, en particular sobre empobrecidos a quienes las piedades elegíacas de antes ya no les servían y que más bien solicitaban, frente al gran panorama de decrepitud antropológica que el poeta decía testimoniar por aquellos años, un nuevo tipo de intervención: la "bufonería piadosa" (OC I, p. 653, p. 664), forma retórica que el "clash" estético había comenzado a asumir en Baudelaire, modo superior (o último) que tomó en él la parataxis. 
"La República representaba para él la BANALIDAD, la opresión de la calidad por la cantidad" (mayúsculas originales; La jeunesse de Baudelaire vue par ses amis, p. 62); esto dijo el amigo de juventud Jules Buisson a propósito del autor de Las flores del mal; y también: "Conocemos el desprecio y el odio que Baudelaire expresaba hacia los republicanos" (p.53). ¿Qué era la República (una República) para Baudelaire? Probablemente, la pregunta se respondiera en los mismos términos de la pregunta vecina, ¿qué era un poema? No había manera de definir nada de ello con certeza, excepto siguiendo la vía analógica practicada hacía decenios por el invisible precursor F. Schlegel, vía que había sido instintiva en Baudelaire: "La poesía es un discurso republicano; un discurso que es en sí mismo su propia ley y su propio fin, y del que todas sus partes son ciudadanos libres con derecho a pronunciarse para ponerse de acuerdo" (Fragmentos críticos, p. 65). La forma de la República ideal, de la República perdida, coincidía punto por punto con el arte que algunos "faros" habían emitido, y en particular con la forma del libro que Baudelaire compuso pero que nunca llegó a ver, esa estructura hecha de partes infinitamente análogas y equivalentes en la que la igualdad absoluta se realizaba del mismo modo que en la solicitación schlegeliana: El Esplín de París. En términos reales, jamás había habido sobre la Tierra una República que pudiera acomodarse a la descripción ideal implicada en el fragmento de Schlegel (o en el libro póstumo de Baudelaire, por caso); ni siquiera la Primera República que la Convención constitucional de 1792 Nº 8. Primer Semestre de 2018 
había promulgado algunos años antes del fragmento citado, habría respondido a esta descripción de la perfección política por vía de un equilibrio estético; hubiese sido imposible que bajo el terror republicano de Robespierre, alguien pensara contar con libertad suficiente como para pronunciarse con el fin de acordar algo, sin que el derecho a la guillotina contestase de inmediato la insolencia.

Manifiestamente, la práctica de concebir constituciones se había convertido para Baudelaire en otro elemento más que reforzaba su teoría (benjaminiana avant la lettre) de la historia: "la verdadera civilización no está ni en el gas, ni en el vapor, ni en las mesas giratorias; está en la disminución de las huellas del pecado original" (OC I, p. 697). En otros términos, la verdadera civilización practicaba la infidelidad sistemática hacia su propio origen; la sociedad olvidaba a la comunidad, "muriendo de aquello por lo que la había creído vivir" (OC I, p. 653). Incluso las constituciones que más parecían contribuir al rescate del último de los cuerpos de Estado, como aquel miserable del poema "Azotemos a los pobres", eran parte del decorado teatral del Progreso y contribuían por tanto a maquillar la decrepitud que el poeta notaba por doquier. La "Declaración de derechos del hombre y del ciudadano", de 1793, había afirmado en su artículo primero que "el fin de la sociedad es la dicha común"; la "Constitución del año III", de 1795, también en su artículo primero había establecido que "las dichas sociales del hombre son la libertad, la igualdad, la seguridad, la propiedad". Tras el momento de distancia retórica de tiempos del Consulado napoleónico, a partir de 1799, y sobre todo del Primer Imperio, a partir de 1804, 
períodos durante los cuales el afecto gubernamental se había desplazado del papel consensuado al área discrecional del Emperador en persona (otra vez, como en las autocracias de tiempos pretéritos, el retorno a la "piedad que llovía de los tronos", según el verso célebre de Shakespeare), la misma Monarquía de julio, en su "Carta Constitucional" del 14 de agosto de 1830, declaraba con un aplomo engañoso, que "los franceses son iguales ante la ley"; e incluso más tarde, durante el lapso tragicómico de la Segunda República, la "Constitución de 1848", no sin un cierto paternalismo que Baudelaire debió haber hallado entre ridículo y repudiable, definía en su Preámbulo, sección VII, que "los ciudadanos deben amar a la patria". Tanta dicha y tanto amor obligados, tanta igualdad afirmada pero irreal, solamente podían inspirar en el poeta la reacción natural del golpe, del azote, como cuando seres queridos, a quienes se les ha confiado algo importante que celar, fallan en su tarea y lo echan todo a perder. ¿Cómo no castigar, entonces, cómo no apalear, golpear, azotar, a un pueblo que no había sido capaz de hacer lo necesario para impedir el desplome de la República?

La República perdida que el poeta, como la negra del poema "El cisne", parecía buscar "detrás de las murallas inmensas de la bruma" (OC I, p. 87), ese resto irrecuperable de verdad histórica alojado en ningún lugar (en el espacio irónico, móvil, huidizo, de una historia que estaba siempre por detrás o por delante del sujeto, nunca en su presente, y que no obstante lo movía infinitamente, desde el deseo), ese lugar imaginario había sido entrevisto por Baudelaire (entre otros sitios) en un poema en prosa tres años anterior a "Azotemos a los pobres": 
"El Bromista" (número IV en la colección póstuma de 1869). Este texto perplejo, que prácticamente nulas observaciones ha suscitado en las ediciones de Kopp y de Pichois, porta no obstante una clave para acceder al quiebre constitutivo de aquel espacio espectral, nunca presente y sin embargo impostergable. Abusando de la "prostitución fraternitaria" (OC I, p. 314), un bromista ocasional decide honrar la consigna republicana de la igualdad saludando con respeto enfático, teatral (como a otro ciudadano más), a un asno que justo pasaba por allí. Tras el saludo irrisorio, el bromista retorna al grupo al que pertenecía, buscando su aprobación, luego sale del cuadro. Queda el poeta irritado y solitario frente a la escena vacía, rabiando "contra este magnífico imbécil que me pareció concentrar todo el espíritu de Francia" (OC I, p. 279; "El bromista"). ¿Cómo no indignarse? El poeta (el speaker o "alma supuesta de escritura", según la expresión notable de Gustave Bourdin, primer reseñador de Las flores del mal) detesta desde siempre toda consigna que hable de igualdad, fraternidad o libertad, por ser derechamente ridículas en contraste con lo que acontecía en el afuera civil; no por ello, sin embargo, se debía suponer que "prostituir" ante un animal esas consignas constituía la mejor forma de refutar la indignidad histórica que ellas habían llegado a portar. No estaban esas consignas, después de todo, para ser convertidas en un sarcasmo mal dirigido, o para postular su anomalía mediante un procedimiento de fábula de cuarta categoría. Era el bromista mismo quien de hecho se había rebajado al nivel a-político del asno; ${ }^{3}$ y si la consigna no había sido honrada como se debía

\footnotetext{
${ }^{3}$ El texto baudelairiano insiste llamativamente en la moda vestida por este insolente
} 
por el lamentable devenir histórico de la nación, de ningún modo su ineficacia podía quedar expuesta al mal uso por parte de un "imbécil" de ese tenor, por ese elemento epidémico de la "fase de vulgaridad de Francia" (OC I, p. 182; "Proyectos de prefacio, II"). Era el poeta quien se arrogaba el monopolio sobre esa crítica, de allí su rabia inconsolable; después de todo, ¿podía ese imbécil igualarse con el poeta en el deseo de ver plasmada en la calle, tras el furor del 48, la fuerza que aquellas consignas habían sabido transmitir por las calles electrizadas de París? Pero ahora, hechas añicos contra la realidad, caídas del cielo moral de las utopías, ¿cómo tolerar que un asno antropomorfo las arrastrara insolentemente por el "fango del macadam" (OC I, p. 352; "Pérdida de aureola")? La historia era tan seria para Baudelaire como su propia soledad, dirigida a la manera de una lanza quijotesca, mellada más no inocua, contra los mil rostros civiles de la decadencia; la República perdida estaba para Baudelaire, como lo había estado antes para Schlegel, en el "espacio literario", fragmentario, intermitente, que solamente la poesía, modo superior del deseo político, llegaba a formular en raras ocasiones.

chancero: sus ropas son visiblemente costosas, y aun así él porta una corbata roja, ensaña del "cuarentayochismo": se trata, evidentemente, de un republicano liberal, personaje ambiguo que podía tener reservas hacia la noción de ciudadano (como las había tenido antes Chateaubriand) y al mismo tiempo profesar un republicanismo moderado. En este sentido, "Azotemos a los pobres" podría funcionar como el complemento caracterológico perfecto de "El bromista": el primero, introduciendo a un agente secreto (cuasi-anarquista) y a un miserable (desterrado de la igualdad real, de la democracia prometida y postergada), el segundo, a un republicano de derecha (liberal de estilo lamartiniano que, proveniente de la Monarquía de julio, tendría fuertes motivos para detestar la parte revolucionaria del movimiento de 1848) y a un asno. La escena parece estar así completa.

$N^{\circ}$ 8. Primer Semestre de 2018 
Mentar la República extraviada en el tiempo, era también aludir a la acción perdida que solamente podía fundarla. Aquel acto llevado a cabo por Baudelaire-personaje una cierta tarde a la entrada de un cabaret y sobre la "antigua carcaza" de un mendigo cualquiera, tenía asimismo su propia tradición en los registros literarios del deseo político. ¿Qué es una acción pura, una acción perdida que imagine ser la posibilidad de reponer el proyecto extraviado de una perfección política? ¿Cuál es la acción que de repente decide, en una suerte de Convención constitucional de uno, o de dos, refundar improvisadamente la República en el espacio diminuto de una puerta de cabaret y en el momento relampagueante de cinco minutos violentos? Es la acción sin ideología, una acción perpetrada por fuera de toda naturaleza segunda, de todo sistema de demoras; es la acción de un pliegue de historia (es decir de texto) tan violento como el que aquella inspira. El contrario exacto de este tipo de acción, y que permite pensar sus equilibrios éticos, sería entonces una potencia pura, una resistencia a devenir acto, a convertirse en fuente de agenciamientos, aunque por los mismos motivos que habían presidido en hipótesis la pureza de aquella acción. El caso de potencia pura puede hallarse, de acuerdo con Agamben, en el personaje Bartleby, de Herman Melville. Bartleby y Baudelaire-personaje representarían por tanto el negativo y el positivo perfectos de la potencia y de la acción puras, respectivamente. Restarse en secreto como identidad, pero no como sujeto, a un proyecto de Estado, a la manera de Bartleby en la lectura agambeniana, debería ser lo 
mismo, en consecuencia, que la operación inversa, emprendida por Baudelaire-personaje en la trama de su poema: sumar al mismo Estado, o a su proyecto, el acto concreto de un sujeto sin identidad, sin ficción de historia (el del agente secreto). Es esto, no otra cosa, el Tiqqun del nuevo ingenuo: la reposición imprevista de "lo político" barthesiano ("la dimensión misma de lo real", como el crítico decía), en el seno de una "política" viciada, la instalación o happening (la performance) de una República "flasheada" de improviso entre dos, una instantánea del no-tiempo de la verdad comunitaria, irrumpiendo violentamente en el presente social (como en la estética del teatro invisible). Aquella sed de acción que la generación romántica, con vocación de memoria y de deseo, había anhelado pero también resignado, era finalmente recuperada, si bien de modo lateral, marginal, desde los bordes sociales, es decir en los únicos lugares en los que la sociedad se dejaba entrever por un instante como comunidad huidiza (como en los perritos belgas o en algunos grupos de miserables). Esta busca o reivindicación, este Tiqqun, era semejante en Baudelaire al deseo de encontrar por fin una "forma de vida" que expresase su apego radical a la existencia ("he was searching for a form of life", estableció Eliot en su "Baudelaire" de 1930). Y fue quizás esta necesidad de hallar esa forma inhallable, de dar con esa acción perdida, lo que condujo al poeta a imaginar sus soluciones finales, estéticas, al problema de la falta comunitaria de las sociedades, plegando por virtud poética escenas espaciales que procedían de contextos en extremo apartados. En su fase final de "comedización de la Piedad", esos "clashes" o soluciones 
paratácticas, habían sido en parte una objetivación o exteriorización de su bipolaridad constitutiva (la diseminación exterior de sus procesos psíquicos), pero también les habían servido al poeta para compensar alucinatoriamente aquella "forma de vida" buscada pero inhallable (excepto en la poesía). El cisne en plena calle polvorienta de París pensando en su lago natal, la negra tanteando cocoteros tras espesos muros de bruma, el agente secreto asaltando una tarde a un mendigo en la puerta de un cabaret, un asno y un imbécil enmarcados por la deuda histórica de la Segunda República, todas estas formas compuestas hablaban para Baudelaire la lengua híbrida de las "bufonerías piadosas" (OC I, p. 653; Cohetes V). Una pintura de Velázquez, El triunfo de Baco (1629), podría ser quizás el mejor antecedente de esta lengua cuya semiótica solamente consigue realizarse en los armónicos superiores de una cultura, jamás en el nivel pedestre de sus códigos. En ella, un dios frío, de impecabilidad se diría parnasiana, posa lúcido e indiferente (un "dandy" entre miserables) junto a unos borrachos que a todas luces ignoraban de qué modo jugar el arte del placer. Un mismo vino dignificaba allí a un dios obsceno y destruía alegremente a las criaturas andrajosas que se habían reunido para adorarlo; la crueldad y la compasión se volvían indiscernibles de tan próximas en esta pintura cuyo sentido último, como en "Azotemos a los pobres", coincidía con la superficie misma de su manifestación inmediata, elemental, haciendo que la parte piadosa y la parte bufona, que el sarcasmo y la caridad, se volviesen sobre sí sin solución de 


\section{continuidad, sin producir fondos ad-hoc que recibiesen e hiciesen retumbar el mensaje. ${ }^{4}$}

${ }^{4}$ El Hiperrealismo conceptual del cuadro de Velázquez supo poner de manifiesto la relación de ambigüedad que cada tanto afecta intensamente al arte y a la realidad. Cuando arte y realidad danzan demasiado separados, se vuelve preciso reunirlos si se quiere que el primero sea el sitio en el que los estados generales, presentes del sujeto se actualicen de manera rotunda; y esto a riesgo de que el arte, en caso de renuencia, devenga una práctica de decorado al asumir su propia vía paralela como si se tratara de una realidad segunda, autónoma, autosuficiente ("autonímica", diría Barthes). El cuerpo casi exánime del arte debe recibir cada tanto estos golpes de electrocución que lo pondrán nuevamente de pie y que lo obligarán, al menos por un tiempo, a moverse (algunos dirán torpemente) según el ritmo de lo real, incorporándolo (a este último) en sus formas bajo el aspecto de colores fuertes, muchas veces salvajes, que parecerán deformarlo y que por cierto lo deformarán (puesto que sólo esa incorporación, perpetrada como a disgusto, permitirá luego a los mejoradores de la práctica hallar un nuevo punto de equilibrio, "innovativo", entre arte y realidad). Aquello que la pintura de Velázquez expresó (quiero decir, entre los varios sentidos que en su forma puedan discernirse), fue sobre todo la necesidad de imprimirle a su práctica el sentido de aquella misma actualización que dos siglos más tarde, en Baudelaire, el poema en prosa que aquí se comenta expresaría también, por medio de la convivencia inopinada, en el "marco" brevísimo, pictórico, de unos pocos párrafos, de un agente culto y secreto (un intelectual muy sui generis para los tiempos post-republicanos, de alcurnia iluminista) y un miserable, tipo subjetivo suficientemente diseminado aunque mucho menos habituado a desplazarse por las páginas de un texto literario). En la historia estética universal de estos coscorrones ocasionales con los que la realidad "azota" cada tanto al arte, podría incluirse también el Neorrealismo italiano de la segunda posguerra, que Rossellini inventó por pura deseperación (baudelairiana) de narrar a los golpes lo vivido. Y es, curiosamente, sólo tras este proceso de actualizaciones a menudo bruscas, salvajes, que el arte se siente repentinamente apto para recapitular, con una parsimonia que asusta, el proceso de alejamiento del que hacía muy poco había retornado no sin algo de culpa. De acuerdo con una dialéctica de distancias que remite a las que Baudelaire experimentó, el arte (de la mano de Pasolini respecto de Rossellini, y antes de la mano de Mallarmé respecto de Baudelaire), supone entonces estar lo suficientemente maduro como para volver a transitar un camino nuevamente paralelo; y ello porque (según suele decir este "nuevo" arte) él sabe muy bien ahora de qué modo hacerse cargo de su propio camino sin exponserse a errores notables. Luego, todo aquello que por fuerza resultará negado en estas nuevas formas estéticas políticamente más "maduras", todo aquello que habrá quedado acumulado en alguna zona irrepresentada de lo real, irrumpirá de pronto en estas nuevas formas que suponían haber digerido bien el salvajismo previo y que resultarán otra vez quebradas pese a sus precauciones. Este otro rondó estético ocurrirá invariablemente: del mismo modo que Baudelaire supo "azotar" la autocomplacencia del Romanticismo en su fase pequeñoburguesa, sentimental, un nuevo arte, insospechado, aparecerá para quebrar en su momento la madura doctrina.

$N^{\circ}$ 8. Primer Semestre de 2018 
A medida que el rondó de la existencia del poeta aceleraba y también achicaba sus giros, el "Lejos de ellos" de 1861 ("Loin d'eux", en el soneto "Recogimiento") aprendía a convivir, por 1865, con el "bien cerca" ("tout près") de las "bufonerías piadosas", suma paradójica que incluía su propia resta y que daba lugar, por tanto, a un cerca y a un lejos simultáneos; porque en esta fase de "comedización de la Piedad", el poeta era también, por fin, otro "transeúnte" o "paseante" más, otro Espectro que ahora circulaba "pegado en pleno día" a los demás Espectros. El trato hacia los otros, hacia el contenido de ese "ellos" que lo había agobiado en otros tiempos, evitaba a partir de aquí toda condescendencia y también todo desprecio (excepto que la condescendencia se contaminase de un sarcasmo o el desprecio de una caridad); por orden de estos "clashes" que el poeta producía como última respuesta estética al abismo político del presente, el otro era ya un "igual real" para este poeta que finalmente había devenido un "semejante", un no hipócrita "hermano", entre los miembros de la comunidad del Número y del Espectro; él mismo, podría decirse, en actitud de "clash" físico con sus congéneres en el desamparo.

* El presente texto forma parte de un libro de su autoría, no publicado aún: Bandelaire o la comedia de la Piedad. 


\section{Referencias Bibliográficas}

Baudelaire, Ch., Correspondance, t. I et II (1973). Paris: Gallimard (Pléiade).

Baudelaire, Ch., Oeuvres complètes, t. I et II (1975, 1976). Paris: Gallimard (Pléiade).

Baudelaire, Ch. Petits poëmes en prose (1973). Ed. Robert Kopp. Paris: Gallimard.

Benjamin, W., Charles Baudelaire. Un poète lyrique à l'apogée du Capitalisme (1982). Trad. De Jean Lacoste. Paris: Payot.

Labarthe, P., Commentaire aux Petits poèmes en prose de Charles Baudelaire (2000). Paris: Gallimard.

Lacoue-Labarthe, Ph., et Jean-Luc Nancy, L'absolu littéraire. Théorie de la littérature du romantisme allemand (1978). Paris: Éditions du Seuil.

Pichois, C. (ed.), La jeunesse de Baudelaire vue par se samis (1991). Nashville: Vanderbilt University Press.

Schlegel, F., Fragmentos críticos (véase Lacoue-Labarthe, Ph., et Jean-Luc Nancy). 